\title{
EFIKASI VERTICILLIUM LECANII UNTUK MENGENDALIKAN PENYAKIT KARAT PADA CAKRAM DAUN KOPI DI LABORATORIUM
}

\author{
Cipta Ginting ${ }^{1}$ dan Subli Mujim ${ }^{1}$
}

\begin{abstract}
Efficacy of Verticillium lecanii to prevent the incidence of rust on coffee leaf disks in the laboratory. In the coffee plantations, Verticillium colonies often develop on the uredium and urediospores of $H$. vastatrix causing coffee leaf rust. The objective of this study was to determine the efficacy of $V$. lecanii to prevent disease incidence on coffee leaf disks in the laboratory. Leaf samples showing lesions with $H$. vastatrix uredospores and whitish mycelium expected to be Verticillium were taken from two coffee fields at Sumberjaya Subdistrict, West Lampung, and transported in ice chest to the laboratory. Verticillium was isolated with a sterilized needle and grown on PDA-lactic acid media (PDA-L). Verticillium was identified as $V$. lecanii as reported previously. In the first test, each of two isolates of $V$. lecanii was grown on media containing yeast extract, malt, peptone-water, and dexytrose (YMPD) to produce conidia. In the second and third tests, each of five antagonistic isolates was grown on PDA-L. Suspension with $10^{7}$ conidia $\mathrm{ml}^{-1}$ was sprayed into leaf disks and then the disks were inoculated with urediospores $\left(10^{4} \mathrm{ml}^{-1}\right)$. In the first test, disease incidence was significantly reduced. However, in the second and third tests, the disease was not significantly reduced.
\end{abstract}

Key words: Verticillium lecanii, Hemileia vastatrix, coffee leaf rust, mycoparasitism

\section{PENDAHULUAN}

Salah satu kendala dalam pengembangan kopi Arabika (Coffea arabica L.) ialah penyakit karat daun, yang disebabkan oleh Hemileia vastatrix B. Br. Penyakit ini biasanya dikendalikan secara budidaya seperti penanaman lini atau jenis yang tahan, pemupukan seimbang, dan pengurangan naungan serta secara kimia dengan menggunakan fungisida (Semangun, 2000). Pengendalian secara budidaya saja kadang-kadang belum memberikan hasil yang memuaskan sehingga masih perlu diaplikasikan fungisida. Pengendalian penyakit secara kimia dengan berbagai fungisida mahal dan dapat menimbulkan dampak negatif terhadap lingkungan serta dapat gagal jika lingkungan sangat mendukung perkembangan penyakit. Oleh karena itu, perlu ditemukan cara pengendalian yang efektif sekaligus efisien dan tidak berdampak negatif terhadap lingkungan seperti pengendalian hayati.

Verticillium lecanii merupakan salah satu antagonis yang berpotensi menjadi agensia pengedalian hayati (Heale, 1997; Kiss, 2003). Sebelumnya telah dilaporkan (Mujim et al., 2005) bahwa Verticillium sering ditemukan pada koloni $H$. Vastatrix yang menimbulkan gejala penyakit karat pada daun kopi. Jamur antagonis ini lebih sering ditemukan pada tanaman kopi dengan banyak naungan dibandingkan dengan yang terjadi pada tanaman dengan sedikit naungan. Keterjadian koloni Verticillium lebih tinggi pada daun yang belum gugur dibandingkan dengan keberadaan koloni pada daun yang sudah gugur. Selain itu, Verticillium yang hidup pada uredium dan urediospora $H$. Vastatrix di Lampung Barat dilaporkan sebagai Verticillium lecanii (Ginting et al., 2006).

Verticillium dapat hidup sebagai mikoparasit dari uredospora dan uredium $H$. pastatrix dan sebagai saprofit dari bahan-bahan organik yang telah mati (Mujim et al., 2005; Semangun, 2000). Akan tetapi, keberadaan Verticillium secara alami saja umumnya tidak dapat mengendalikan penyakit karat daun kopi secara memuaskan. Dengan demikian, perlu dikembangkan metode aplikasi Verticillium di kebun kopi untuk mengendalikan penyakit. Penelitian ini bertujuan untuk mengetahui efikasi $V$. Lecanii untuk mencegah terjadinya penyakit karat daun pada cakram daun di laboratorium.

\section{METODE PENELITIAN}

Isolasi Verticillium dan Penyiapan Inokulum $\boldsymbol{H}$. Vastatrix. Daun kopi yang menunjukkan bilur dan mengandung uredospora $H$. vastatrix dan koloni 
berwarna keputihan, yang diduga Verticillium, dipetik pada tanaman kopi di dua kebun di Sumberjaya, Lampung Barat. Masing-masing sampel daun ditaruh pada kantung plastik dan disimpan dalam termos berisi es selama transportasi ke laboratorium. Dengan cara yang sama, didapatkan daun dengan uredospora tanpa koloni berwarna keputihan sebagai sumber inokulum untuk inokulasi.

Isolasi Verticillium dilakukan dengan mengambil miselium berwarna keputihan tersebut dengan jarum steril dan memindahkannya ke cawan petri yang mengandung PDA-asam laktat (PDA-L). Inkubasi dilakukan pada suhu $23-26{ }^{\circ} \mathrm{C}$ dengan periode cahaya 12:12 jam. Kultur murni dibuat dengan metode ujung hifa (hyphal tips) dan disimpan pada agar miring yang mengandung media PDA.

Uji Antagonisme pada Cakram Daun Kopi. Percobaan ini dilakukan untuk mengevaluasi efikasi isolat agensia hayati Verticillium untuk mencegah terjadinya karat pada cakram daun di laboratorium. Uji antagonisme dilakukan tiga kali. Pada Percobaan 1, diuji efikasi dua isolat V. Lecanii (J6 dan J11), sedangkan pada masing-masing percobaan kedua dan ketiga diuji enam isolat (A1, B1, C1, C2, C3, dan J11). Pada Percobaan 1, konidia jamur Verticillium diproduksi dalam media cair yeast extract, malt, peptone-water, and dexytrose (YMPD) seperti yang dilaporkan Askary et al. (1997) dengan bahan-bahan per liter media sebagai berikut: $3 \mathrm{~g}$ ekstrak ragi, $3 \mathrm{~g}$ malt, 5 g peptone-water, dan $10 \mathrm{~g}$ dekstrosa. Media cair ini digunakan untuk menumbuhkan jamur pada shaker selama 14 hari. Pada akhir inkubasi kultur disaring dengan tiga lapis kain kasa steril untuk memperoleh suspensi konidia. Konsentrasi disesuaikan menjadi $10^{7}$ konidia $\mathrm{ml}^{-1}$ dengan aquades steril. Pada Percobaan 2 dan 3, untuk memproduksi konidia $V$. lecanii yang ditumbuhkan pada media padat PDA-L. Cuplikan miselium ditumbuhkan pada media PDA-L pada suhu $23-26{ }^{\circ} \mathrm{C}$ selama 7 hari. Konidia dipanen dan disiapkan suspensi konidia $\left(10^{7}\right.$ $\mathrm{ml}^{-1}$ ) pada aquades steril.

Cakram daun kopi berdiameter $2 \mathrm{~cm}$ disemproti dengan suspensi konidia agensia hayati yang telah disiapkan tersebut. Perlakuan kontrol ialah cakram yang disemproti dengan aquades steril. Setelah kering udara, setiap cakram daun diinokulasi dengan $20 \mu 1$ suspensi yang mengandung $4 \times 10^{5}$ uredospora $\mathrm{ml}^{-1}$ (berdasarkan hasil sebelumnya) diteteskan pada masing-masing cakram daun.

Inkubasi dilakukan dalam nampan yang pada dasarnya telah diberi kertas hisap dan air steril dan ditutup dengan kaca transparan setebal $4 \mathrm{~mm}$ untuk menjaga kelembaban (Ginting et al., 2002). Perlakuan disusun dalam rancangan acak kelompok dengan sebuah nampan sebagai satu kelompok karena pada percobaan sebelumnya terjadinya variasi pada hasil percobaan antar-nampan. Unit percobaan (experinmental unit) terdiri atas delapan cakram daun dan cakram daun untuk satu kelompok disusun dalam satu nampan. Inkubasi dilakukan pada suhu 23-26 ${ }^{\circ} \mathrm{C}$. Pengamatan dilakukan setiap hari selama 4 minggu. Peubah yang diamati ialah keterjadian penyakit, yang dihitung dengan rumus x/y x 100\% dengan $\mathrm{x}$ sebagai jumlah cakram daun bergejala dan y jumlah cakram per unit percobaan. Data yang diperoleh dianalisis dengan uji $F$ dan jika hasil uji Fnya nyata dilanjutkan dengan uji Duncan $(\mathrm{P} \leq 0,05)$.

\section{HASIL DAN PEMBAHASAN}

Pada semua percobaan, gejala penyakit tampak 3 minggu setelah inokulasi (msi). Gejala tersebut berupa bilur berwarna kekuningan yang mulai dari bagian tengah cakram daun. Penyakit berkembang baik dalam bentuk meluasnya gejala pada masingmasing cakram daun maupun dalam jumlah cakram yang bergejala.

Pada Percobaan 1, isolat J6 dan J11 secara nyata menurunkan keterjadian penyakit $3-4 \mathrm{msi}$ (Tabel 1). Pada Percobaan 2 dan 3, uji F atas data keterjadian penyakit menunjukkan bahwa perlakuan

Tabel 1. Efikasi $V$. lecanii isolat J11 dan J6 untuk mengendalikan karat pada cakram daun kopi pada Percobaan 1

\begin{tabular}{ccc}
\hline \multirow{2}{*}{ Perlakuan } & \multicolumn{2}{c}{ Keterjadian penyakit (\%) $3-4$ minggu setelah inokulasi ${ }^{1)}$} \\
\cline { 2 - 3 } & 3 & 4 \\
\hline Kontrol & $33,3 \mathrm{a}$ & $41,7 \mathrm{a}$ \\
J6 & $0,0 \mathrm{~b}$ & $0,0 \mathrm{~b}$ \\
J11 & $8,3 \mathrm{~b}$ & $8,3 \mathrm{~b}$ \\
\hline
\end{tabular}

\footnotetext{
${ }^{\bar{T}}$ Angka yang diikuti huruf yang sama tidak berbeda nyata menurut uji Duncan $(\mathrm{P} \leq 0,05)$
} 
tidak menimbulkan pengaruh nyata.

Beberapa laporan sebelumnya (a.1. Yun et al., 1991) menunjukkan adanya potensi jamur ini sebagai agensia hayati untuk mengendalikan penyakit penyakit karat. Tampaknya mekanisme hiperparasitisme atau antibiosis terjadi dalam penekanan jamur patogen oleh Verticillium. Hiperparasitisme terjadi pada interaksi antara V. lecanii dan Sphaerotheca fuliginea (Schlectend.:Fr) Pollacci yang menyerang mentimun (Cucumis sativus L.) dengan proses sebagai berikut: pelengketan (attachement) antagonis $V$. lecanii pada patogen $S$. fuliginea, tekanan mekanik dan produksi enzimpencerna-dinding-sel-patogen oleh antagonis seperti kitinase, penetrasi dan pertumbuhan aktif $V$. lecanii dalam tubuh $S$. fuliginea, pencernaan jaringan patogen, dan keluarnya antagonis dari sel-sel patogen yang telah mati. Proses parasitisme itu berlangsung dengan cepat. Dua puluh empat jam setelah terjadi kontak antara antagonis $V$. lecanii dan patogen $S$. fuliginea, sudah tampak pengaruh negatif antagonis berupa bertambahnya vakuola dalam sel (peningkatan vacuolation). Setelah $36-48$ jam vakuola terus meningkat dan timbul ruang kosong pada haustoria patogen. Kemudian, setelah 72 jam, haustoria rusak dan menjadi nekrotik (Askary et al. (1997).

Lebih daripada itu, Priyatmojo (1989) dalam Semangun (2000) menemukan bahwa Verticillium dapat menghambat perkecambahan dan infeksi uredospora Hemileia. Leguizamon-C et al. (1989) dalam Mawardi (1996) melaporkan bahwa ekstrak jamur $V$. lecanii menekan laju perkecambahan uredospora, memperlama masa inkubasi, menurunkan derajat infeksi, dan menurunkan produksi spora. Temuan ini mengindikasi-kan mekanisme antagonisme $V$. lecanii sebagai antibiosis di samping sebagai parasit (hiperparasitisme). Pada jamur patogen lain (Penicillium digitatum), seperti dilaporkan oleh Benhamon and Brodeur (2000), terdapat bukti ultrastruktural dan sitokimia pertama bahwa antagonisme akibat $V$. lecanii berlangsung dalam proses yang kompleks dengan antibiosis sebagai proses penentu. Dalam antibiosis tersebut, terjadi perubahan hifa patogen $P$. digitatum sebelum terjadi kontak antara kedua jamur itu.

Hasil Percobaan 1 (Tabel 1) sejalan dengan keterangan tentang daya antagonisme $V$. lecanii (Yun et al., 1991; Askary et al., 1997) bahwa dua isolat $V$. Lecanii mengurangi keterjadian penyakit secara nyata. Akan tetapi, hasil Percobaan 2 dan 3 menunjukkan bahwa perlakuan tidak berpengaruh nyata terhadap keterjadian penyakit. Dari enam isolat yang diuji, tidak ada isolat yang secara nyata menurunkan keterjadian penyakit karat pada cakram daun kopi. Isolat $\mathrm{J} 11$, yang pada Percobaan 1 menurunkan keterjadian penyakit secara nyata cenderung menurunkan keterjadian penyakit, namun penurunan tersebut tidak nyata menurut uji $\mathrm{F}$.

Perbedaan hasil percobaan antara Percobaan 1 (Tabel 1) dan Percobaan 2 dan 3 (masing-masing Tabel 2 dan 3) mungkin disebabkan karena perbedaan prosedur yang digunakan dalam penyiapan konidia $V$. lecanii. Pada Percobaan 1, suspensi konidia agensia hayati tersebut disiapkan pada media cair (media YMPD), sedangkan pada Percobaan 2 dan 3 konidia disiapkan pada media padat (PDA-L). Masih perlu diteliti faktor nutrisi dan penyediaan inokulum di laboratorium termasuk untuk mengetahui apakah prosedur penyiapan konidia ini berpengaruh terhadap daya antagonisme $V$. Lecanii.

Prosedur uji efikasi seperti yang dikemukakan pada Metode dilakukan karena aplikasi agensia hayati

Tabel 2. Efikasi enam isolat $V$. lecanii untuk mengendalikan karat pada cakram daun kopi pada Percobaan 2

\begin{tabular}{ccc}
\hline \multirow{2}{*}{ Perlakuan } & \multicolumn{2}{c}{ Keterjadian penyakit (\%) $3-4$ minggu setelah inokulasi ${ }^{1)}$} \\
\cline { 2 - 3 } & 3 & 4 \\
\hline Kontrol & 58,3 & 65,0 \\
J11 & 40,4 & 60,8 \\
C1 & 40,0 & 49,2 \\
C2 & 37,5 & 60,8 \\
C3 & 58,3 & 66,7 \\
B1 & 70,8 & 83,3 \\
A1 & 83,3 & 87,5 \\
\hline
\end{tabular}

${ }^{\mathrm{T}} \mathrm{Uji} \mathrm{F}$ atas data keterjadian penyakit tidak berbeda nyata $(\mathrm{P} \leq 0,05)$ 
Tabel 3. Efikasi enam isolat $V$. lecanii untuk mengendalikan karat pada cakram daun kopi pada Percobaan 3

\begin{tabular}{ccc}
\hline \multirow{2}{*}{ Perlakuan } & \multicolumn{2}{c}{ Keterjadian penyakit (\%) $3-4$ minggu setelah inokulasi ${ }^{1)}$} \\
\cline { 2 - 3 } & 3 & 4 \\
\hline Kontrol & 50,8 & 62,5 \\
J11 & 12,5 & 12,5 \\
C1 & 25,4 & 27,5 \\
C2 & 54,2 & 58,3 \\
C3 & 50,0 & 60,4 \\
B1 & 25,0 & 45,8 \\
A1 & 42,5 & 45,0 \\
\hline
\end{tabular}

${ }^{\Gamma} \mathrm{Uji} F$ atas data keterjadian penyakit tidak berbeda nyata $(\mathrm{P} \leq 0,05)$

dengan cara ini dapat secara langsung menekan uredospora. Dalam patosistem penyakit karat daun kopi, uredospora sebagai inokulum sekunder merupakan penyebab parahnya penyakit. Infeksi primer biasanya kurang berpengaruh, namun akan menghasilkan inokulum sekunder berupa uredospora tersebut. Dalam pada itu, kepadatan inokulum (dalam hal ini uredospora) mempengaruhi keterjadian penyakit (Agrios, 2005; Semangun, 2000). Jika antagonis Verticillium tinggi populasinya pada daun dan memarasiti uredia dan uredospora, maka kepadatan uredospora (inokulum sekunder) akan menurun sehingga infeksi sekunder juga menurun.

\section{SIMPULAN}

Pada percobaan pertama, dua isolat $V$. lecanii yang diuji (J6 dan J11) secara nyata menurunkan keterjadian penyakit karat pada cakram daun kopi di laboratorium 3-4 msi. Pada percobaan kedua dan ketiga, dari enam isolat yang diuji (A1, B1, C1, C2, $\mathrm{C} 3$, dan J11), tidak ada isolat yang secara nyata menurunkan keterjadian penyakit karat pada cakram daun kopi.

\section{SANWACANA}

Tulisan ini melaporkan sebagian hasil penelitian yang didanai dari Proyek RUT XI. Untuk itu, penulis menyampaikan terima kasih kepada Pengelola Proyek RUT XI Penulis juga menyampaikan terima kasih kepada Wiyadi (alm.) dan keluarga yang mengizinkan penulis untuk memanfaatkan kebun kopinya menjadi tempat penelitian, kepada Rusdi Evizal atas masukan di lapangan, kepada Titik Nur Aeny atas masukan perbaikan naskah, serta kepada Bayu Sunuaji, Farida
Ariani dan Tri Maryono atas bantuan teknis di laboratorium dan di lapangan.

\section{DAFTAR PUSTAKA}

Agrios, G.N. 2005. Plant Pathology. $5^{\text {th }}$ Ed. Elsevier Academic Press, Burlingkton, MA. $922 \mathrm{pp}$.

Askary, H., N. Benhamou \& J. Brodeur. 1997. Ultrastructural and cytochemical investigations of the antagonistic effect of Verticillium lecanii on cucumber powdery mildew. Phytopathology 87:359-368.

Benhamou, N. \& J. Brodeur. 2000. Evidence for antibiosis and induced host reactions in the interaction between Verticillium lecanii and Penicillium digitatum, the causal agent of the causal agent of green mold. Phytopathology 90:932-943.

Ginting, C., A. Gafur \& R. Evizal. 2002. Beberapa hasil inokulasi pada cakram daun kopi dengan Hemileia vastatrix di laboratorium. J. HPT Tropika 2:26-31.

Ginting, C., S. Mujim, \& A.H. Dianto. 2006. Spesies Verticillium yang berasosiasi dengan Hemileia vastatrix pada daun kopi. J. Natur Indonesia 8:114 - 117 .

Heale, J.B. 1997. Diversification and speciation in Verticillium - an overview. Pages 1- 14 in Tjamos et al. Eds. Advances in Verticillium: 
Research and disease management. APS Press, St. Paul, Minnessota.

Kiss, L. 2003. A review of fungal antagonists of powdery mildews and their potential as biocontrol agents. Pest Manag Sci 59:475-483.

Mawardi, S. 1996. Kajian Genetika Ketahanan Tak Lengkap Kopi Arabika terhadap Penyakit Karat Daun (Hemileia vastatrix B. et $\mathrm{Br}$.) di Indonesia. Disertasi. Universitas Gadjah Mada, Yogyakarta.
Mujim, S., R. Ruswandi, C. Ginting, \& R. Evizal. 2005. Asosiasi keterjadian koloni Verticillium dan intensitas naungan serta letak daun kopi. $J$. HPT Tropika 5:32-36.

Semangun, H. 2000. Penyakit-penyakit Tanaman Perkebunan di Indonesia. Edisi kedua. Gadjah Mada University Press, Yogyakarta. 835 hlm.

Yun, Y., P.D. Bridge \& H.C. Evans. 1991. An integrated approach to the taxonomy of the genus Verticillium. J. Gen. Microbiol. 137:1437-1444. 